\begin{tabular}{|c|c|c|}
\hline (S) & $\begin{array}{c}\text { Türkiye Tarımsal Araştırmalar Dergisi } \\
\text { dergipark.gov.tr/tutad }\end{array}$ & $\begin{array}{l}\text { Turk J Agric Res } \\
\text { 2018, 5(3): 209-221 } \\
\text { ๑ TÜTAD } \\
\text { ISSN: 2148-2306 }\end{array}$ \\
\hline $\begin{array}{l}\text { UNIVERSiTESI } \\
\text { Bilimin Dyüunda }\end{array}$ & Research Article & $\begin{array}{l}\text { e-ISSN: 2528-858X } \\
\text { doi: } 10.19159 / \text { tutad.407623 }\end{array}$ \\
\hline
\end{tabular}

\title{
Extreme Processing Conditions Applied in Selection of Different Microorganisms Utilized as Compost Enhancers
}

\author{
Fadime ÖZDEMİR KOÇAK ${ }^{1 *}$, Levent DEĞíRMENCİ ${ }^{2}$ \\ ${ }^{1}$ Bilecik Şeyh Edebali University, School of Health, Department of Nursing, Bilecik, TURKEY \\ ${ }^{2}$ Bilecik Şeyh Edebali University, Faculty of Engineering, Department of Chemical and Process Engineering, Bilecik, TURKEY
}

\begin{tabular}{ll}
\hline \multicolumn{1}{c}{ Received: 19.03 .2018} & Accepted: 12.10 .2018 \\
\hline ORCID ID (by author order) & \\
\hline Dorcid.org/0000-0002-8557-5166 Dorcid.org/0000-0001-6608-0398 & \\
"Corresponding Author: fadime.ozdemirkocak@bilecik.edu.tr
\end{tabular}

\begin{abstract}
Present study included isolation of microorganisms during the mesophilic stage of composting and their reuse in compost mixture to enhance organic matter degradation. Effect of microorganism addition on compost degradation was investigated in the presence of microorganisms obtained by isolation from a miniscule composting system. Effects of water addition and time of mixing were applied as extreme composting conditions. Isolates were obtained from these systems and inoculated to determine the most resistant microorganisms. 16S rRNA sequencing of selected strains indicated the presence of Escherichia, Enterococcus and Streptomyces genus. These microorganisms were added to a large-scale compost mixture to accelerate degradation of organic matter. Results indicated 20 and 38\% decreases of organic matter in the sole utilization of Streptomyces sp. K1P07 and ternary utilization at the end of 14 days. Escherichia and Enterococcus inhibited degradation in the case of binary utilization. Isolation of microorganisms from the original flora of the compost mixture had accelerated composting due to interaction among themselves. Member of Actinomycetes, in particular, was shown to be effective even in the case of sole utilization. Higher amounts of biomass-oriented wastes could be removed since composting would be terminated in shorter times with the use of these microorganisms.
\end{abstract}

Keywords: 16S rRNA gene sequencing, Escherichia sp., Enterococcus sp., Streptomyces sp., composting

\section{Introduction}

Composting can be defined as a series of reactions leading to consecutive decomposition and stabilization of organic matter. Microorganisms involved in the process operate at varying temperature ranges. Composting process advances in phases known as mesophilic, thermophilic and maturation. The process is feasible and can be applied economically for the removal of biomass oriented hazardous wastes which is the main reason for its popularity (Białobrzewski et al., 2015). The main parameters effective in the process are temperature (Białobrzewski et al., 2015), moisture and aeration (Yuan et al., 2016). These parameters should continuously be monitored in order to maintain high efficiency.

Feasibility in application is among the advantages of composting. This process could even be applied in the presence of organic household wastes. Home composting has become popular due to the increase in organic wastes generated in home, gardens, and plantations. Sustainable management of these wastes in Spain was investigated in the work of Vázquez and Soto (2017) in which an average $77 \%$ efficiency in the reduction of organic matter was achieved by composting household waste (Vázquez and Soto, 2017).

Chestnut forest green, pig manure (Arias et al., 2017), poultry manure (Liu et al., 2017), grape marc (Paradelo et al., 2013), cattle manure with sawdust and rice hull (Lim et al., 2017), green wastes with kitchen remnants (Neugebauer and Sołowiej, 2017) are among the examples of organic wastes used in composting. Optimization of parameters (Białobrzewski et al., 2015; Yuan et al., 2016), availability of various biomass (Arias et al., 2017; Lim et al., 2017), decrease of greenhouse gas 
emissions (Lim et al., 2017; Liu et al., 2017; Meng et al., 2017), obtaining pathogen-free compost mixtures (Pandey et al., 2016) and recently acceleration of composting process (Manu et al.,2017) are among the topics being investigated in composting.

Identification of the microbial diversity in a compost mixture is considered as an important step leading to the determination of microorganisms used as compost enhancers. Microbial diversity is greatly influenced by the type of soil present in the mixture and also interaction between the soil and microorganism greatly influence the flora of the compost mixture (Kent and Triplett, 2002; Krishnan et al., 2017). Although rare, there are also studies on microorganism addition to compost mixtures for their acceleration. Effects of microbial inoculum addition and waste mixing in compost mixtures were studied in a drum composting system composed of wet food waste. Results indicated faster decomposition of compost mixture when supplemented with microorganisms (Manu et al., 2017).

Literature survey presented so far showed that various microorganisms could have been utilized in low temperature composting to accelerate degradation of the organic content (Awasthi et al., 2016). The present study will contribute to these studies by introducing microorganisms with possible uses in low temperature composting. The present study is divided into two parts. Initially, microorganisms were isolated from a miniscule composting system consisted of solid cake, Alfalfa plant, and soil. The solid cake, obtained during olive oil production, is selected as the main carbon source with the intention of proposing an alternative for its removal. Conventional press mill method utilized in the production of olive oil was recently replaced by two-phase extraction to reduce water needs. However, using this new method resulted in the production of a solid cake which was basically a biomass with polyphenols, oil and organic acids in its structure. This organic residue has high potential as a feedstock component in compost applications (Canet et al., 2008; Delgado-Moreno and Peña, 2009). Alfalfa plant is rich in nitrogen which is crucial for microorganism growth and soil is considered as the main source of microorganisms constituting the compost flora. Effect of watering, mixing up time and aeration on microbial flora was determined with these miniscule systems. The conditions applied in watering and aeration were extreme and selected for the determination of the strains which were resilient to harshest conditions. $\mathrm{pH}$ of these mixtures were kept between 6-8 at all times.
Extreme conditions such as low watering and late mixing of compost mixture represent misapplication in compost preparation. Compost could easily be prepared by home users and farmers. However, once the ingredients of the mixture were added, preparation requires a meticulous procedure of watering and mixing up. Differences in the handling of compost mixture could alter the amount of organic matter degradation and time of composting.

The second part of the study contained preparation of conventional compost mixtures and inoculation of the microorganisms selected in the first part. We have prepared compost mixtures without addition of microorganism and compared its performance with microorganism added systems. The idea was to add the most resilient microorganisms with the intention of obtaining higher organic matter decomposition in their presence. The compost mixture used in this second part consisted of solid cake, sheep manure and soil. The ingredients and amounts of the components in the mixture was adjusted to maintain temperature on the threshold of mesophilic stage.

\section{Materials and Methods}

\subsection{Preparation of the medium for microorganism flora and microorganism isolation procedure}

Compost mixture utilized in the first part of the experiment consisted of solid cake, Alfalfa plant, and soil. The amounts of the components were adjusted to obtain an initial $\mathrm{C} / \mathrm{N}$ ratio of 30 . The initial moisture content of each ingredient was measured with an analyzer prior to mixing in order to calculate the total amount of water in the mixture. Amount of water to be added was determined based on this calculation.

During composting, the moisture content of the compost mixture was measured with a commercially available, portable moisture analyzer which was designed for outdoor use. The levels of the device were Dry, Dry + , Normal, Wet, Wet + which corresponded to $<20,20-40,40-60,60-80$ and $>80 \%$ moisture levels. The aim was to maintain conditions that were also applicable for daily use of farmers or operators of home composting. Compost mixtures were moisturized by addition of water at the beginning of the process and composting was conducted for only 1 week. Our intention was not to obtain mature compost in this stage of the experiment but to promote a suitable medium for mesophilic microorganisms to thrive.

Compost mixtures were turned up for aeration in certain time periods. These periods were selected 
as every day (daily), 3 and 7 days. Samples were taken after aeration at the end of designated time intervals. These intervals were selected based on the behavior of a hardworking (daily), responsible (3 days) and lazy farmers (7 days). In addition, samples from the $0^{\text {th }}$ day of compost were also taken to fully investigate the effect of aeration on microorganism flora. Sampling was conducted in each water/compost regimes.

Samples were collected and placed in a sterilized container. They are divided into two equal parts and one half is heat-treated at $55^{\circ} \mathrm{C}$ for 30 minutes while no treatment was applied to another half. Isolation of these samples was accomplished by utilization of conventional isolation method, the details of which were given elsewhere (Sembiring et al., 2000). Initially, $1 \mathrm{~g}$ of the sample was diluted to $10 \mathrm{ml}$ ringer solution and further dilution was conducted to $10^{-2}$ and $10^{-3}$ fold by addition of ringer solution. These dilutions were then inoculated to specific mediums at $30^{\circ} \mathrm{C}$. The obtained microorganisms were morphology examined at the end of 14 days. The aeration time added water amount, the details of applied isolation procedure on heat treated and untreated isolates were given in Table 1. Untreated isolates were added to the study with the intention of observing the microorganisms in entire microbiota.

Table 1. Mixing and moisture conditions applied on compost mixtures, inoculation media utilized in heat treated and untreated samples

\begin{tabular}{|c|c|c|c|}
\hline \multirow{2}{*}{$\begin{array}{l}\text { Amount of } \\
\text { water added/ } \\
\text { compost } \\
\text { amount }\end{array}$} & \multirow[b]{2}{*}{$\begin{array}{c}\text { Aeration } \\
\text { time }\end{array}$} & \multicolumn{2}{|c|}{ Inoculation medium $^{*}$} \\
\hline & & $\begin{array}{l}\text { Heat-treated } \\
\text { samples }\end{array}$ & $\begin{array}{l}\text { No } \\
\text { treatment }\end{array}$ \\
\hline \multirow[t]{4}{*}{$1 / 1$} & $0,3,7$ & $\mathrm{NA}+\mathrm{C}+\mathrm{R}$ & $\mathrm{NA}+\mathrm{C}$ \\
\hline & daily & $\mathrm{LB}+\mathrm{C}+\mathrm{R}$ & $\mathrm{LB}+\mathrm{C}$ \\
\hline & & $\mathrm{TSA}+\mathrm{C}+\mathrm{R}$ & $\mathrm{TSA}+\mathrm{C}$ \\
\hline & & $\mathrm{SM} 3+\mathrm{C}+\mathrm{R}+\mathrm{N}$ & $\mathrm{SM} 3+\mathrm{C}$ \\
\hline \multirow[t]{4}{*}{$1 / 4$} & $0,3,7$ & $\mathrm{NA}+\mathrm{C}+\mathrm{R}$ & $\mathrm{NA}+\mathrm{C}$ \\
\hline & daily & $\mathrm{LB}+\mathrm{C}+\mathrm{R}$ & $\mathrm{LB}+\mathrm{C}$ \\
\hline & & $\mathrm{TSA}+\mathrm{C}+\mathrm{R}$ & $\mathrm{TSA}+\mathrm{C}$ \\
\hline & & $\mathrm{SM} 3+\mathrm{C}+\mathrm{R}+\mathrm{N}$ & $\mathrm{SM} 3+\mathrm{C}$ \\
\hline \multirow[t]{4}{*}{$2 / 1$} & $0,3,7$, & $\mathrm{NA}+\mathrm{C}+\mathrm{R}$ & $\mathrm{NA}+\mathrm{C}$ \\
\hline & daily & $\mathrm{LB}+\mathrm{C}+\mathrm{R}$ & $\mathrm{LB}+\mathrm{C}$ \\
\hline & & $\mathrm{TSA}+\mathrm{C}+\mathrm{R}$ & $\mathrm{TSA}+\mathrm{C}$ \\
\hline & & $\mathrm{SM} 3+\mathrm{C}+\mathrm{R}+\mathrm{N}$ & $\mathrm{SM} 3+\mathrm{C}$ \\
\hline
\end{tabular}

*NA: Nutrient Agar; LB: Luria Broth Agar; TSA: Tryptic soy broth agar; SM3: Gauze's medium; C: Cycloheximide; R: Rifampicin; N: Nalidixic acid

\subsection{Selection of microorganisms}

Microorganisms with the highest number of colonies were morphologically determined from isolate plates. These isolates were obtained by sampling from compost mixtures in various time and aeration intervals. Colonies obtained from these mixtures were then purified by inoculation in the same medium.

Initial results of the morphological determination revealed the presence of Actinomycetes and Bacillus type species. Consequently, different medium for different microorganisms should be used for exact morphological determination. Microorganisms, indicating similar characteristics, were inoculated in ISP media 2-7 (Shirling and Gottlieb, 1966) and LB medium (Lennox, 1955).

\subsection{Composting experiments}

Selected microorganisms were activated in glucose yeast extract broth at $30^{\circ} \mathrm{C}$ for 7 days. The broth was kept in rotary shaker during inoculation. Glass beads were also added to each flask to prevent clump formation during cultivation. Cultivated microorganisms were diluted $1: 10$ to give an approximate concentration of 0.5 McFarland standard based on the recommendations of the National Committee of Clinical Laboratory Standards (Anonymous, 2003).

Composting experiments were conducted with a mixture of sheep manure, solid cake, and soil. The amounts were determined as $75 \%$ sheep manure, $20 \%$ solid cake and $5 \%$ soil based on dry basis $(\mathrm{C} / \mathrm{N}$ ratio of 30 ). The $\mathrm{C} / \mathrm{N}$ ratio was identical to the miniscule system. The moisture of the mixtures was kept above $\% 50$ by constant water addition in a 7-day period. The temperature was monitored daily to prevent possible transition to the thermophilic stage. The samples were turned on every 3 days to maintain constant aeration.

The change in parameters was investigated for 14 days. This time was determined based on the time of temperature stabilization. Samples were collected every 7 days and their organic content and $\mathrm{C} / \mathrm{N}$ ratio were determined in comparison with control. Elemental analyses were conducted in LECO CHNS-932 device. Organic contents of the samples were determined with standardized method (Anonymous, 2014). FT-IR analyses of the samples obtained in 7-day period were conducted with a Cary 630 Fourier transform infrared spectrometer, equipped with a single reflection diamond attenuated total reflectance (ATR) accessory. Results obtained from these analyses were evaluated in accordance with organic content analyses.

\subsection{DNA extraction, $16 \mathrm{~S}$ rRNA sequencing, and phylogenetic analysis}

$16 \mathrm{~S}$ rRNA sequencing of the strains with code numbers of $\mathrm{K} 2 \mathrm{P} 05, \mathrm{~K} 0 \mathrm{P} 22$, and $\mathrm{K} 1 \mathrm{P} 07$ was conducted. These are the strains selected for use in 
compost mixtures. The assignment of code numbers and selection of these strains were elaborated in Results and Discussion section. Incubation of the strains for DNA extraction was achieved in tryptone-yeast extract glucose broth at $30^{\circ} \mathrm{C}$, for 6-8 days. 16S rRNA sequencing procedure consisted of a series of steps including chromosomal DNA isolation (Pitcher et al., 1989), PCR amplification (Lane, 1991) and construction of phylogenetic tree via a neighbor-joining algorithm (Jukes and Cantor, 1969; Saitou and Nei, 1987; Tamura et al., 2013). The contents of PCR solution and the primers used in PCR and sequencing were given in Table 2 and Table 3, respectively.

Table 2. The content of PCR solution and parameters used in the thermal amplification

\begin{tabular}{|c|c|c|}
\hline $\begin{array}{l}\text { PCR solutions } \\
(50 \mu \mathrm{l})\end{array}$ & $\begin{array}{l}\text { Primers }(20 \mu \mathrm{M} \text {, Invitrogen }) \\
\text { Deoxynucleoside triphosphate mixture }(25 \mu \mathrm{M} \text {, Promega) } \\
\text { Taq polymerase tampon (HotstarTaq, QIAGEN) } \\
\text { Taq polymerase }(2.5 \mathrm{U} \text {, HotstarTaq, QIAGEN) } \\
\text { Chromosomal DNA }(50-300 \mathrm{ng})\end{array}$ & \\
\hline Amplification parameters & $\begin{array}{l}1 \min , 95^{\circ} \mathrm{C} ; 2 \min , 55^{\circ} \mathrm{C} ; 3 \min , 72{ }^{\circ} \mathrm{C} \text {; } \\
35 \text { cycles }\end{array}$ & $\begin{array}{l}10 \text { min, } 72^{\circ} \mathrm{C} \text {; } \\
1 \text { cycle }\end{array}$ \\
\hline
\end{tabular}

Table 3. Primers used in PCR and sequencing for $16 \mathrm{~S}$ rRNA

\begin{tabular}{llll}
\hline Primer & Sequence (5' and 3') & Size (bp) & Utilization \\
\hline $800 \mathrm{r}$ & TACCAGGGTATCTAATCC & 18 & Sequence \\
MG3f & CAGCAGCCGCGGTAATAC & 18 & Sequence \\
MG5f & AAACTCAAAGGAATTGACGG & 20 & Sequence \\
$27 \mathrm{f}$ & AGAGTTTGATCTGGCTCAG & 20 & Amplification \\
$1525 \mathrm{r}$ & AAGGAGGTGWTCCARCC & 17 & Amplification \\
\hline
\end{tabular}

\section{Results}

Determination of microorganism diversity in threshold conditions was highly challenging. We have investigated the effect of mixing time, water addition, effect of heat treatment prior to isolation. These effects were investigated for isolates obtained with and without antibiotics supplementation. A large set of plates was used in experiments, the plates were coded according to water/compost ratio $(\mathrm{K} 0, \mathrm{~K} 1$ and $\mathrm{K} 2$ for water/compost ratios of $1 / 1,1 / 4$ and $2 / 1$, respectively) and the type of utilized antibiotics and media were also written on the plates (Table 4). We have intended to select microorganisms which had highest resistivity in extreme conditions. In our opinion, these microorganisms could maintain their existence in every condition and therefore should be considered as fine candidates for compost application.

The images of microorganisms were given in Supplementary file (see Supplementary figure). We have selected certain images to illustrate the effect of heat treatment prior to isolation, mixing time and water/compost ratio. In the case of isolates obtained without heat treatment, the entire microbiota should be governed by Bacillus genus and mold formation which was true for untreated samples (Figure 1; images on the right). These results indicated the effect of heat treatment even in the presence of antibiotics, however mixing time could also be responsible for the decrease in kind and number of microorganisms along with mold and Bacillus genus formation. Consequently, effect of mixing time was investigated for the samples obtained in the presence of heat treated and antibiotics supplemented media and results indicated mold and Bacillus sp. formation initiating after 3 days of mixing (Figure 1; images on the left).

Amount of water added to compost mixture had altered the amount and variety of Actinomycetes observed in plates (Figure 2a, b, c; See Supplementary Figure for more images). Mold formation was not observed in the presence of excess water (water/compost: 2/1), as expected. Aeration time had negligible effect on the mold formation compare to watering. This could be the case as the growth of these eukaryotic microorganisms could not be possible in the presence of excess water. However, Bacillus genus like formation could still be observed even in highest watering conditions (Figure 2d, e, f). Mold formation could not be eliminated even with low watering conditions. Mold was mainly observed in the plates inoculated from the samples mixed with 3 and 7 days interval (Figure 2g, h, i).

Actinomycetes had large numbers and variety in various mixing and water/compost ratios. However, only one Actinomycete sp. was common for $1 / 1$ and $4 / 1$ compost/water ratio which was inoculated in LB-R/C medium. These microorganisms could only be determined in identical mediums and were the only microorganism common in isolates (Figure 3a, 
Table 4. Media and antibiotics, pre-process (heat treated and untreated), mixing time of collected samples and isolates code used in the study

\begin{tabular}{|c|c|c|c|c|c|}
\hline Code & Isolate code & $\begin{array}{l}\text { Isolation } \\
\text { medium }\end{array}$ & Antibiotics & Treatment & Mixing time \\
\hline \multicolumn{6}{|c|}{ K0 } \\
\hline 1 & К0Р01 & NA & $\mathrm{R}-\mathrm{C}$ & Heat & K \\
\hline 2 & К0Р02 & NA & $\mathrm{R}-\mathrm{C}$ & Heat & 3 \\
\hline 3 & К0Р03 & NA & $\mathrm{R}-\mathrm{C}$ & Heat & 7 \\
\hline 4 & К0Р04 & NA & R-C & Heat & 0 \\
\hline 5 & К0Р05 & LB & $\mathrm{R}-\mathrm{C}$ & Heat & 0 \\
\hline 6 & К0Р06 & LB & $\mathrm{R}-\mathrm{C}$ & Heat & 0 \\
\hline 7 & К0Р07 & TSA & $\mathrm{R}-\mathrm{C}$ & Heat & 3 \\
\hline 8 & К0Р09 & TSA & $\mathrm{R}-\mathrm{C}$ & Heat & 0 \\
\hline 9 & K0P10 & TSA & $\mathrm{R}-\mathrm{C}$ & Heat & 0 \\
\hline 10 & K0P12 & LB & $\mathrm{R}-\mathrm{C}$ & Heat & 3 \\
\hline 11 & K0P13 & LB & $\mathrm{R}-\mathrm{C}$ & Heat & 3 \\
\hline 12 & K0P14 & SM3 & N-R-C & Heat & $\mathrm{K}$ \\
\hline 13 & K0P15 & SM3 & N-R-C & Heat & 0 \\
\hline 14 & K0P16 & LB & $\mathrm{R}-\mathrm{C}$ & Heat & 3 \\
\hline 15 & К0Р17 & LB & $\mathrm{R}-\mathrm{C}$ & Heat & 3 \\
\hline 16 & K0P18 & LB & $\mathrm{R}-\mathrm{C}$ & Heat & 7 \\
\hline 17 & К0Р19 & LB & $\mathrm{R}-\mathrm{C}$ & Heat & 0 \\
\hline 18 & K0P20 & NA & $\mathrm{R}-\mathrm{C}$ & Heat & 0 \\
\hline 19 & K0P21 & TSA & $\mathrm{R}-\mathrm{C}$ & Heat & 0 \\
\hline 20 & K0P22 & TSA & $\mathrm{R}-\mathrm{C}$ & Heat & 7 \\
\hline 21 & K0P23 & TSA & $\mathrm{R}-\mathrm{C}$ & Heat & $\mathrm{K}$ \\
\hline 22 & K0P24 & NA & $\mathrm{R}-\mathrm{C}$ & Heat & 3 \\
\hline \multicolumn{6}{|c|}{ K1 } \\
\hline 23 & K1P01 & TSA & R-C & Heat & 0 \\
\hline 24 & K1P02 & NA & $\mathrm{R}-\mathrm{C}$ & Heat & $\mathrm{K}$ \\
\hline 25 & K1P03 & TSA & $\mathrm{R}-\mathrm{C}$ & Heat & 7 \\
\hline 26 & K1P04 & SM3 & N-R-C & Heat & 0 \\
\hline 27 & K1P05 & SM3 & N-R-C & Heat & 0 \\
\hline 28 & K1P06 & LB & R-C & Heat & 7 \\
\hline 29 & K1P07 & LB & $\mathrm{R}-\mathrm{C}$ & Heat & 7 \\
\hline 30 & K1P08 & LB & $\mathrm{C}$ & - & 0 \\
\hline 31 & K1P09 & LB & $\mathrm{C}$ & - & 0 \\
\hline 32 & K1P10 & LB & $\mathrm{C}$ & - & 0 \\
\hline 33 & K1P11 & NA & $\mathrm{R}-\mathrm{C}$ & Heat & 7 \\
\hline \multicolumn{6}{|c|}{ K2 } \\
\hline 36 & K2P01 & NA & R-C & Heat & 0 \\
\hline 37 & K2P02 & NA & $\mathrm{C}$ & - & 0 \\
\hline 38 & K2P03 & NA & $\mathrm{C}$ & - & 0 \\
\hline 39 & K2P04 & SM3 & N-R-C & Heat & 0 \\
\hline 40 & K2P05 & NA & $\mathrm{R}-\mathrm{C}$ & Heat & 7 \\
\hline 41 & K2P06 & NA & $\mathrm{R}-\mathrm{C}$ & Heat & 0 \\
\hline 42 & K2P07 & LB & $\mathrm{R}-\mathrm{C}$ & Heat & 3 \\
\hline 43 & K2P08 & TSA & $\mathrm{R}-\mathrm{C}$ & Heat & 3 \\
\hline 44 & K2P09 & LB & $\mathrm{R}-\mathrm{C}$ & Heat & 0 \\
\hline 45 & K2P10 & LB & $\mathrm{R}-\mathrm{C}$ & Heat & 7 \\
\hline
\end{tabular}

K0: Samples obtained in the presence of 1/1 water/compost ratio, K1: Samples obtained in the presence of 1/4 water/compost ratio, K2: Samples obtained in the presence of 2/1 water/compost ratio, NA: Nutrient agar, LB: Luria broth agar, TSA: Tryptic soy broth agar, SM3: Gauze's medium, C: Cycloheximide, R: Rifampicin, N: Nalidixic acid

$b, c)$. As seen from the Figure, a code name was used for these and other isolated microorganisms at this stage to prevent confusion of the species, the medium, mixing time and water amount. These codes were identities of isolated microorganisms giving the medium, mixing time and amount of water added (Table 4).
Besides Actinomycetes, two dominant types of microorganisms, illustrated in a red and black circle in Figure 2d, were also observed. These were inoculated in LB/R-C medium along with other types of microorganisms indicating similar characteristics (Figure 3e, f). Selected microorganisms were coded as K2P05 and K0P22 


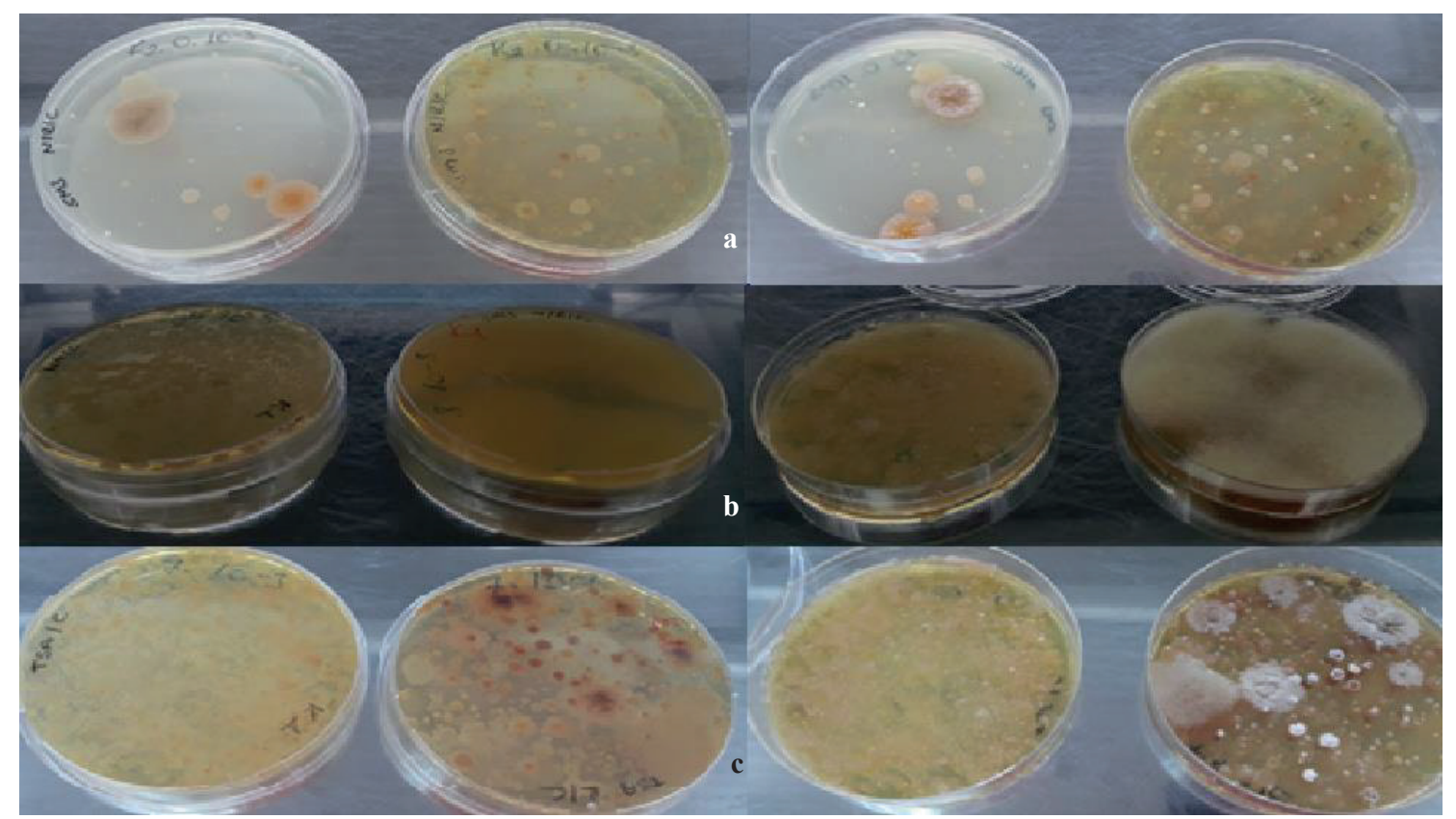

Figure 1. Effect of mixing time on mold and Bacillus genus like formation in the presence of heat treated (on the left, rear views) and untreated (on the right front views) samples. (a) $0^{\text {th }}$ day samples obtained in the presence of SM3 media, (b) $3^{\text {rd }}$ day samples obtained in the presence SM3 media, (c) $7^{\text {th }}$ day samples obtained in the presence of TSA media

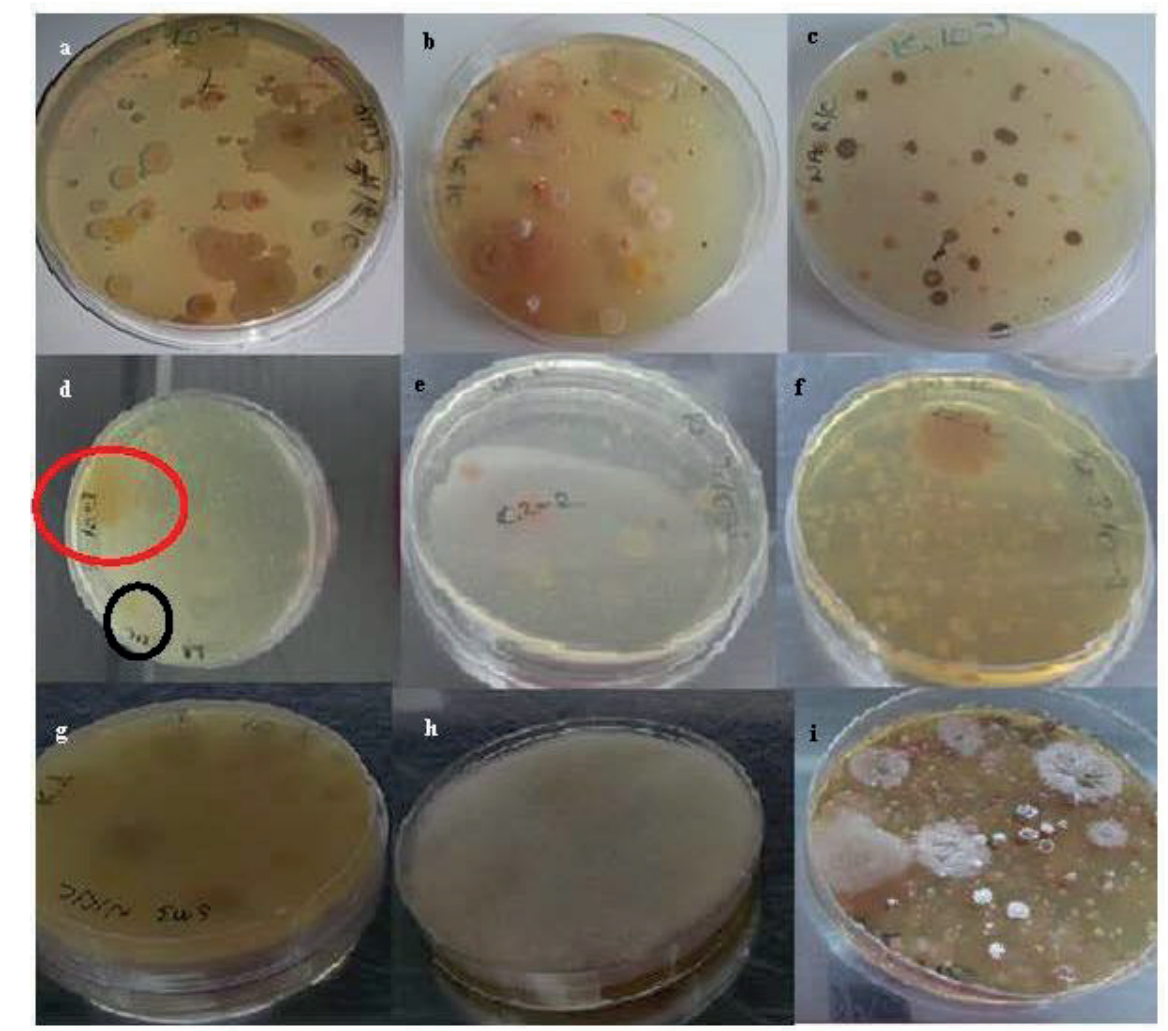

Figure 2. Actinomycetes sp. observed with the isolates prepared with $1 / 4$ water/compost ratio. (a) Rear view (0 days; SM3-N/R/C), (b) Front view (0 days; SM3-N/R/C), (c) Rear view (0 days; NA-R/C). Bacillus genus like microorganisms observed in the isolates taken from 7 and 3 day samples d) rear view (7 days, LB-R/C), (e) Rear view (3 days, TSA-R/C), (f) Rear view (3 days LB-R/C). Mold formation observed with the isolates prepared with 1/4 water/compost ratio g) rear view (3 days, SM3-N/R/C), (h) Front view (3 days, SM3-N/R/C), (i) Front view (7 days, TSA-R/C) 


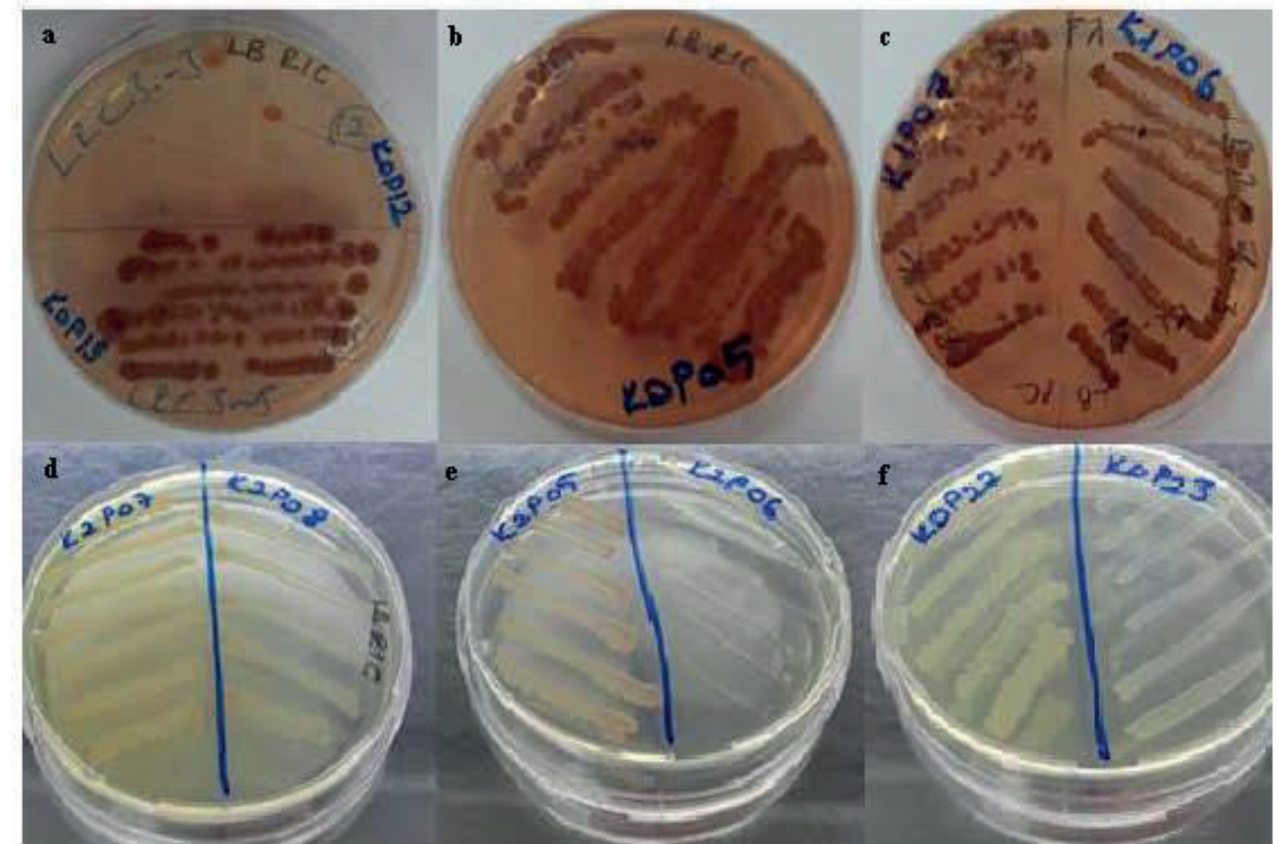

Figure 3. Morphologically identical Bacillus sp. and Actinomycetes as determined in LB-R/C medium, (a) K0P13, (b) K0P05, (c) K1P07, (d) K2P07-K2P08, (e) K2P05-K2P06, (f) K0P22-K0P23

(microorganisms with a red and black circle, respectively) (Figure 2d). Morphological evaluation of these microorganisms implied the presence of Actinomycetes and Bacillus sp. Although the details of $16 \mathrm{~S}$ rRNA sequencing were given below, in this part of the study we felt obliged to state that neither of the selected microorganisms had any resemblance with Bacillus sp. On the other hand, Actinomycete evaluation for K1P07 coded microorganism was turned out to be correct. The microorganisms with code names of K0P23, K2P06, K2P07, and K2P08 in Figure 3 (d, e, f) were inoculated as their numbers were very high in a single medium (LB-R/C) and they were stocked in glycerol solutions for future applications.

Composting experiments were conducted in the presence of selected microorganisms with a mixture of $75 \%$ sheep manure, $25 \%$ solid cake and $5 \%$ soil. The amounts of added microorganisms were determined as 0.5 McFarland for K0P05, K0P22, and K1P07. Microorganism inoculations to composting systems were either applied solely or as a mixture. In the case of sole inoculation, the solution was diluted to $1 \mathrm{~L}$ whereas $500 \mathrm{~mL}$ of binary mixtures and $330 \mathrm{ml}$ of ternary mixtures were utilized in experiments. The codes presented above were altered with letters $\mathrm{A}, \mathrm{B}$ and $\mathrm{C}$ to prevent confusion in interpreting the results. $\mathrm{K}$ letter was used for the control mixture. The codes of the microorganisms used in composting experiments were given in Table 5.
Table 5. Microorganisms utilized in composting experiments

\begin{tabular}{lll}
\hline Isolate code & $\begin{array}{l}\text { The code } \\
\text { used in } \\
\text { composting } \\
\text { experiments }\end{array}$ & $\begin{array}{l}\text { Type of the } \\
\text { species }\end{array}$ \\
\hline K0P05 & $\mathrm{A}$ & Not known \\
K0P22 & $\mathrm{B}$ & $\begin{array}{l}\text { Not known } \\
\text { Actinomycetes sp. }\end{array}$ \\
K1P07 & $\mathrm{C}$ & \\
K0P05-K0P22 & $\mathrm{AB}$ & \\
K0P05-K1P07 & $\mathrm{AC}$ & \\
K0P22-K1P07 & $\mathrm{BC}$ & \\
K0P05-K0P22-K1P07 & $\mathrm{ABC}$ & $\begin{array}{l}\text { Control } \\
\text { (no inoculation) }\end{array}$ \\
\hline & $\mathrm{K}$ &
\end{tabular}

The change in temperature and the variation in the organic content of the compost mixtures were given in Figure 4. Analyses for determination of organic content were conducted at least thrice and average values were used in constructing the figure. The highest temperature during 14-day period was determined as $40^{\circ} \mathrm{C}$ which was the threshold of the thermophilic stage. The temperature was especially held below the threshold to investigate the effects of microorganisms in the mesophilic stage. An increase was observed in temperature until the $7^{\text {th }}$ day after this time, temperature values decreased due to the decrease in mesophilic microbial activity (Figure 4a). The samples used in the determination of the organic content were obtained in $7^{\text {th }}$ and $14^{\text {th }}$ day of the experiment and the change of organic content was given in terms of $\%$ ratio of change at 

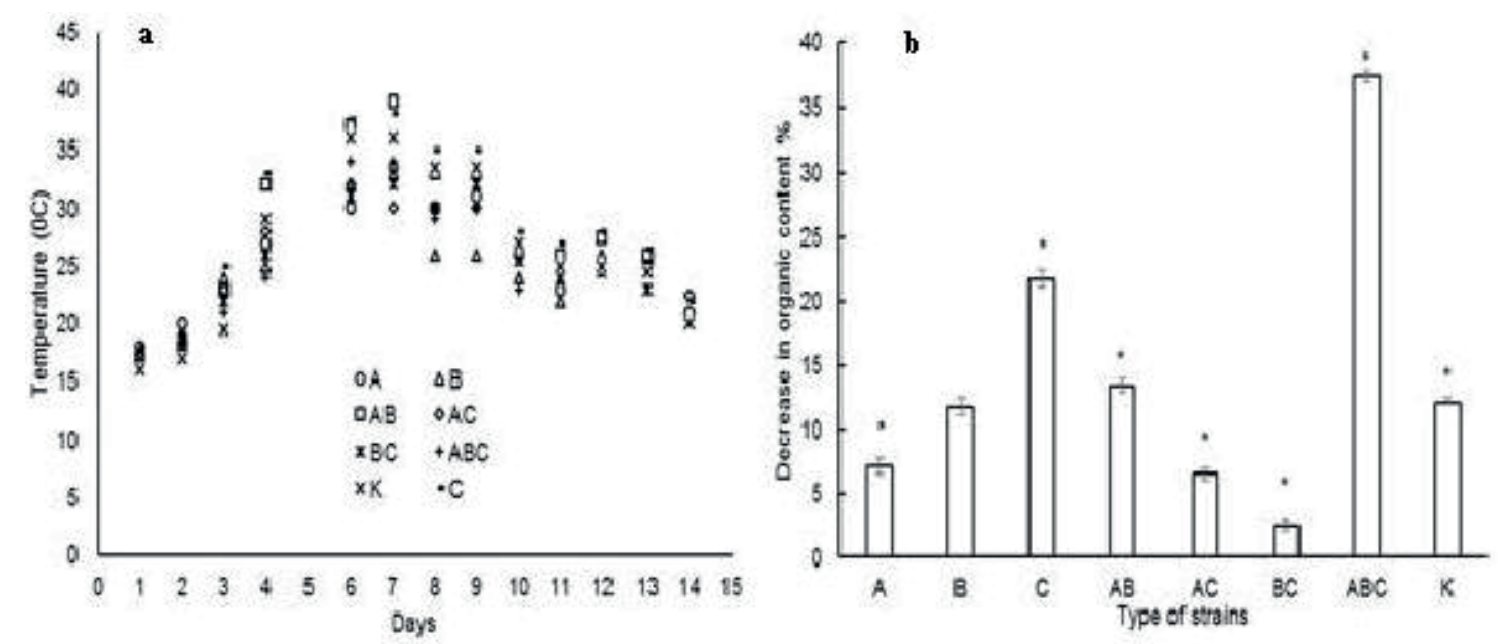

Figure 4. The change in (a) Temperature of compost mixtures determined as the average of 4 measurements from the center (b) Organic content of the mixtures during 14 days of composting

*: indicates significance with $\mathrm{p}<0.001$, B strain was insignificant compared to control, $\mathrm{t}$-test Anova was conducted via Graphpad calculation (trial version) software

the end of 14 days. Results indicated highest activity of Actinomycete (C) in sole utilization. In the case of binary utilization, results indicated lower values due to the presence of $\mathrm{A}$ and $\mathrm{B}$ coded microorganisms (AC and $\mathrm{BC}$ ). Highest decrease in organic content was observed in the case of ternary (ABC) utilization (Figure 4b).

FT-IR analyses of compost samples were conducted in order to validate the results obtained with organic content analyses. FT-IR results of the samples obtained at $14^{\text {th }}$ days of composting experiments were given in Figure 5, the order of presentation was adjusted based on increasing number of organic content with $\mathrm{BC} 14$ being the lowest and $\mathrm{ABC} 14$ being the highest. Results indicated the presence of certain peaks at 1021 ,
1397, 1543, 1636, 2851, 2918 and $3272 \mathrm{~cm}^{-1}$ wavenumber values. These peaks were determined for each sample, for each day of sampling with slight shifts in the values. The peak obtained at 1021 $\mathrm{cm}^{-1}$ corresponded to $\mathrm{C}-\mathrm{O}$ stretching vibrations of polysaccharides (Grube et al., 2006; Tandy et al., 2010; Soobhany et al., 2017). The peak with weak intensity at $1397 \mathrm{~cm}^{-1}$ corresponded to $\mathrm{N}-\mathrm{O}$ vibrations. $\mathrm{C}=\mathrm{C}$ stretching vibrations at $1636 \mathrm{~cm}^{-1}$ indicated the presence of aromatic content. Peak values obtained at 2851 and $2918 \mathrm{~cm}^{-1}$ corresponded to aliphatic methylene groups (Grube et al., 2006; Tandy et al., 2010; Soobhany et al., 2017; Van Fan et al., 2018). The broad band obtained at $3272 \mathrm{~cm}^{-1}$ indicated $\mathrm{O}-\mathrm{H}$ and $\mathrm{N}-\mathrm{H}$ vibrations which were attributed to phenols, alcohols, and amines (Soobhany et al., 2017).

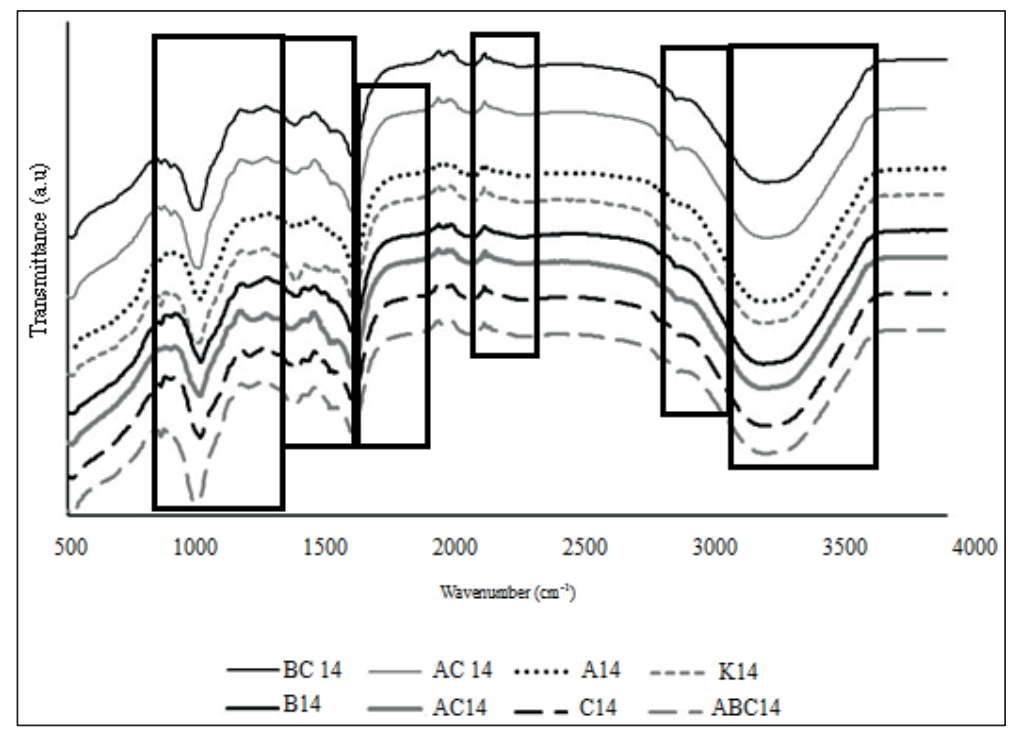

Figure 5. FT-IR analyses of samples obtained at the $14^{\text {th }}$ day of the experiment 
Decomposition of the organic content could not be visually determined by comparison of FT-IR analyses ( $7^{\text {th }}$ and $14^{\text {th }}$ days). However, it was possible to quantitatively evaluate the progress in the stability of the compost by comparing the ratios of 2918/1636 and 2918/1021 peaks. These ratios were determined separately for $7^{\text {th }}$ and $14^{\text {th }}$-day samples and their comparison were illustrated for each sample in Table 6. As previously mentioned, highest decrease in organic content was obtained in the presence of $\mathrm{C}$ and $\mathrm{ABC}$ samples. The slight decrease in 2918/1636 ratios and the increase in 2918/1021 ratios of samples C and ABC indicated completion of the microbial activity. The decrease observed in 2918/1034 and 2918/1636 ratios of B, $\mathrm{AB}$ and $\mathrm{BC}$ samples showed their ongoing, yet slower activity (Grube et al., 2006).

Table 6. Comparison of $2918 / 1034$ and $2918 / 1636$ ratios of $7^{\text {th }}$ and $14^{\text {th }}$-day samples

\begin{tabular}{lccccccccc}
\hline Ratio & A7 & B7 & C7 & AB7 & AC7 & BC7 & ABC7 & K7 \\
\hline $2918 / 1034^{*}$ & 0.25 & 0.35 & 0.29 & 0.33 & 0.31 & 0.27 & 0.28 & 0.33 \\
$2918 / 1636^{*}$ & 0.19 & 0.24 & 0.28 & 0.26 & 0.23 & 0.27 & 0.21 & 0.28 \\
\hline & A14 & B14 & C14 & AB14 & AC14 & BC14 & ABC14 & K14 \\
\hline $2918 / 1034^{*}$ & 0.26 & 0.31 & 0.35 & 0.29 & 0.32 & 0.25 & 0.31 & 0.27 \\
$2918 / 1636^{*}$ & 0.30 & 0.23 & 0.25 & 0.22 & 0.24 & 0.23 & 0.20 & 0.32 \\
\hline
\end{tabular}

*: Some shifts may occur in peak values of different samples

The results of $16 \mathrm{~S}$ rRNA sequencing of selected microorganisms were evaluated by utilization of Neighbor-joining tree algorithm. Results were illustrated in Figure 6 (a, b, c). K0P22 (B) was $99.51 \%$ related to $E$. coli and E. fergusonii (7 nt difference) and $98.66 \%$ related to E. albertii (19 nt difference) (Figure 6a). Another microorganism which was suspected to be a member of Bacillus sp turned out to be a member of Enterococcus genus with $98.81 \%$ relationship to Enterococcus lactis and 98.61\% relationship with Enterococcus faecium (K2P05, coded as A in composting experiments). The nt differences were 17 and 20 which were high values enough to assume the possibility of new species (Figure 6b).

As previously mentioned, K1P07 (coded as C in composting experiments) was thought to be a member of Actinomycetes class based on the morphological determination. 16S rRNA analysis of this species validated our conclusion with $98.55 \%$ relationship to Streptomyces tunisiensis and $97.83 \%$ relationship to $S$. matensis. nt differences were determined as 20 and 31, respectively. New species of Streptomyces genus could be determined even though the resemblance was as high as $99.4 \%$ (Mohammadipanah et al., 2014). Hence, this species with highest nt difference was also considered as a candidate of new species (Figure 6c).

\section{Discussion}

The reuse of selected microorganisms in compost mixtures indicated higher values of degradation compared to control $(\mathrm{K})$ in the presence of sole $(\mathrm{C})$, binary $(\mathrm{AB})$ and ternary $(\mathrm{ABC})$ utilization. The fact that combined utilization of K2P05 and K0P22 (AB) had resulted in higher degradation of organic matter implied that their growth rate is enhanced in the case of co-existence. As seen from Figure $4 b$, lower values in a decrease of organic content were observed in the presence of $\mathrm{AC}$ and $\mathrm{BC}$ microorganisms. Based on these results, it was concluded that $\mathrm{A}$ and $\mathrm{B}$ microorganisms had inhibited the growth of Actinomycetes due to their higher growth rate. Literature survey indicated a doubling time in terms of minutes for certain microorganism genus (Bacillus sp, Escherichia sp, Enterococcus sp.) (Burdett et al., 1986; Prakasham et al., 2006) whereas doubling time for Actinomycetes was measured in hours (Flowers and Williams, 1977). It was our belief that the number of Actinomycetes in microorganism flora was generally lower than A and B which were also observed in isolates (See Figures 1 and 2 for comparison). Consequently, Actinomycetes could not compete with these when added as binary mixtures. On the other hand, highest decrease in organic content was observed in the presence of ternary mixture $(\mathrm{ABC})$ implying the existence of a threshold limit in the amounts of $\mathrm{A}$ and $\mathrm{B}$ microorganisms compared to Actinomycetes (C) (Figure 4b). Further investigations on the determination of optimum content will be conducted in near future. Nevertheless, it would be fair to state that co-existence of these strains, with adjusted amounts, could accelerate composting of biomass. This was one of the highlights of this study as it was shown that composting of biomass could have been accelerated by simply adjusting the amounts of the strains already existed in their original flora.

Based on the changes of $2918 / 1636$ and 2918/1021 ratios obtained from FT-IR analyses, it was concluded that minor changes in organic content should have occurred in the presence of 


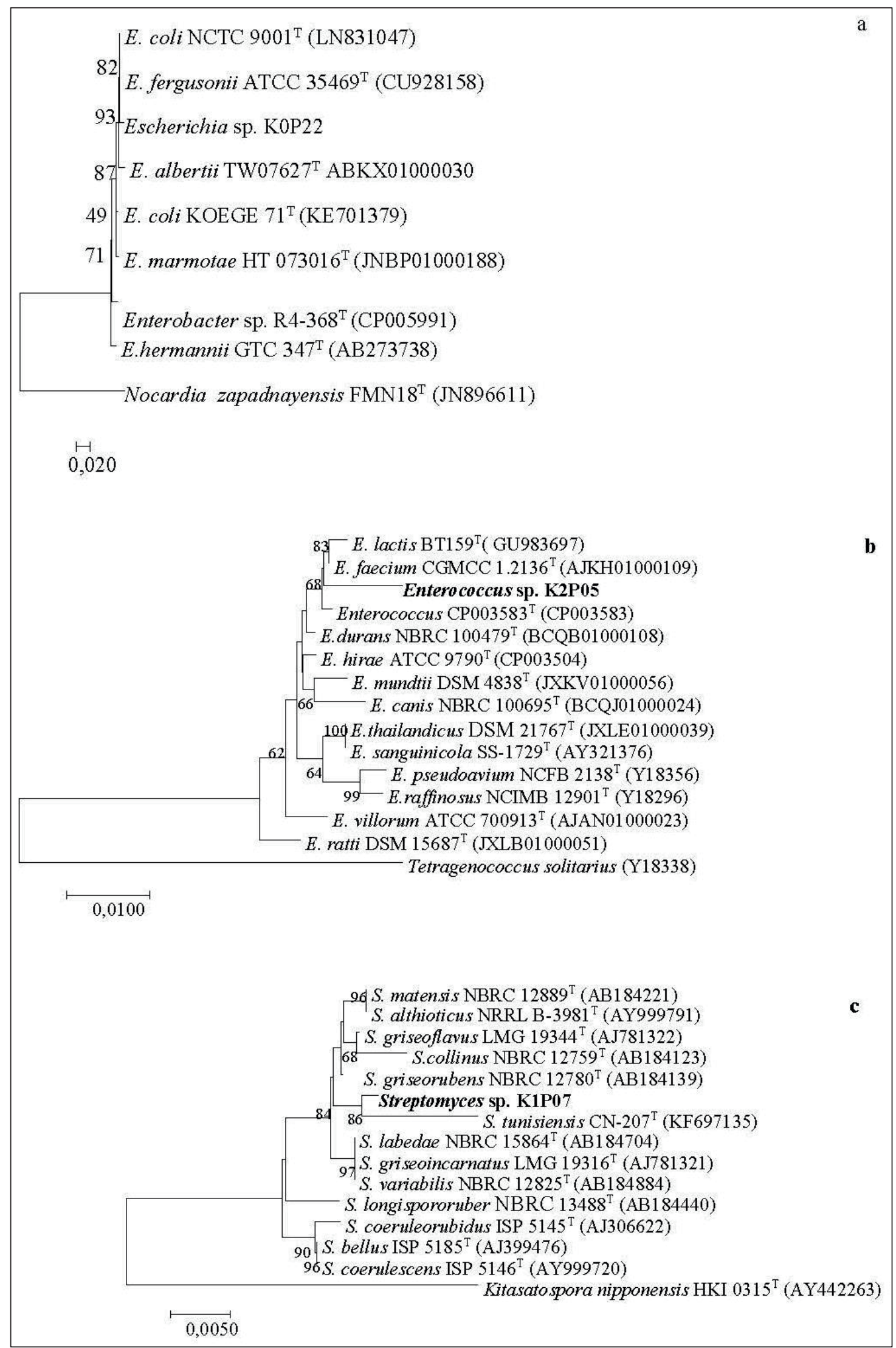

Figure 6. (a) Neighbour-joining tree of K0P22 indicating its resemblance with Escherichia genus,

(b) Neighbour-joining tree of K2P05 indicating its resemblance with Enterococcus genus,

(c) Neighbour-joining tree of K1P07 indicating its resemblance with Streptomyces genus 
either $\mathrm{C}$ or $\mathrm{ABC}$, in maturity phase of composting. Although further experiments were required to validate this result, it was our belief that this had also been one of the highlights of the present study as composting period could have been completed in much lower times with the appropriate addition of microorganisms inside compost mixture (Figure 5).

16S rRNA analyses showed that K1P07 (coded as $\mathrm{C}$ in composting experiments) had indeed been a member of Actinomycetes class. However, K2P05 and K0P22 coded microorganisms (A and B) which was thought to be a member of Bacillus sp turned out to be members of Escherichia and Enterococcus genus, respectively. At first sight, it was interesting to observe microorganisms other than Bacillus sp. However, the determined species were present in the intestinal microbiota of sheep and apart from the fact that sheep manure was used in experiments, the presence of this species should also be expected as soil utilized in composting experiments was collected from cultivated area enriched with sheep manure. The downside of this discovery was the possible pathogen nature of the microorganisms that belonged to Escherichia genus (Tandy et al., 2010). On the other hand, there was a strong possibility of this species being new. There existed only 7 species identified among Escherichia genus and high amount of nucleotide difference implied the possibility of a new species. Further analyses for species determination will be conducted in near future. Utilization of this microorganism was not expected and we could not be able to find any studies related to their use in composting. On the other hand, literature survey indicated an increase in the proliferation of $E$. coli in the presence of biodegradable dissolved organic carbon. This result was interpreted as an indicator for the possible enhancing effect of this microorganism during composting (Figure 6a) (Bouteleux et al., 2005).

K2P05 coded microorganism which was determined to be the member of Enterococcus genus was known as commensal with no harm to human or animal intestinal systems. The high population of this species could also emanate from sheep manure and soil enriched with manure. Species of this genus were recently utilized as probiotic in human and animals. However, it was not considered as "generally recognized as safe" (GRAS) (Araújo and Ferreira, 2013). The bad news for this species was its close relationship with Enterococcus faecium implying the possibility of human infection. This genus was also known to be a member of Bacilli class (Ludwig et al., 2009) which explained misapprehension of morphological analyses (Figure 6b). The effect of this microorganism as compost enhancer was not surprising as a lactic acid bacterium Pediococcus acidilactici TM14, closely related to our isolate, was successfully inoculated in a mixture of rabbit food and organic acids in the work of Tran et al. (2015). Results indicated high levels of acetic acid in bacteria-free mixtures and an enhanced proliferance of fungi due to the growth of TM14 (Tran et al., 2015).

In the case of K1P07, it was our belief that the main source of these strains had been soil. The enzymes of this species were known to be effective in $\mathrm{C}-\mathrm{N}$ cycles due to their high degradation and fixation ability (Gtari et al., 2012; Tang-um and Niamsup, 2012). Hence an accelerated decrease of organic content should be expected with its addition in compost mixtures (Figure 6c).

Microbial interactions between added species should further be investigated with composting experiments. The effects of these microorganisms could further be validated by additional experiments with varying $\mathrm{C} / \mathrm{N}$ ratios. These parameters will be investigated and the results will be presented in near future. Having said that present results indicated enhancing the effect of microorganisms in composting compared to control group. Their interaction, especially in the case of ternary use, resulted in highest degradation of organic content. The highest degradation in the case of ternary use was probably due to varying degradation mechanisms of the organic content. In other words, organic content degraded by a microorganism could be used for the growth of others. Although further studies were required to validate this conclusion we could at least illustrate literature examples of microbial interaction and their effect on composting such as the work of Hou et al. (2017) in which twelve psychotropic strains were utilized in low temperature composting. Results indicated a faster transition to thermophilic phase in the presence of these strains and these strains were also stated to have great influence on the quality of final compost mixture (Hou et al., 2017). In another study conducted by Xie et al. (2017), cold-adapted microbial consortium (CAMC) composed of Pseudomonas fragi (KY283110), Pseudomonas simiae (KY283111), Clostridium vincentii (KY283112), Pseudomonas jessenii (KY283113) and Iodobacter fluviatilis (KY283114) were utilized in the startup of composting. Results indicated high activity of degradation at low temperatures in the presence of these strains (Xie et al., 2017). It was our belief that results obtained with this study had been useful in providing a contribution to ongoing studies.

A two-step composting experiment was conducted with the intent of determining the most 
resistant microorganisms and their reuse in a composting system. Results indicated the highest decrease of organic matter in the presence of single Streptomyces utilization and their ternary utilization compared to control samples. Streptomyces genus was frequently utilized in many areas of biotechnology including compost systems. The high decrease of organic matter due to its utilization was one of the highlights of the study. Although species with high possibility of being pathogen also existed in flora, there is a strong possibility of these and Streptomyces species being new and their identification will be conducted in the nearest future.

\section{Conclusion}

Microbial interactions between added species should further be investigated with composting experiments conducted with varying microorganism ratios and also the effect of these microorganisms could further be validated by composting experiments conducted with varying $\mathrm{C} / \mathrm{N}$ ratios. These parameters will be investigated and the results will be presented in near future. Having said that, present results indicated enhancing effect of microorganisms in composting compared to control group. Their interaction especially in the case of ternary use resulted in highest degradation of organic content which was probably due to varying degradation mechanisms of the organic content. In other words, organic content degraded by a microorganism could be used for the growth of others. Although further studies were required to validate this conclusion we have at least illustrated literature examples of microbial interaction and their effect on composting in "Discussion" section (Hou et al., 2017; Xie et al., 2017). It was our belief that results obtained with this study had been useful in providing a contribution to ongoing studies.

\section{References}

Anonymous, 2003. National Committee for Clinical Laboratory Standards, Performance Standards for Antimicrobial Susceptibility Testing: Eleventh Informational Supplement, M100-s11. National Committee for Clinical Laboratory Standard, Wayne, PA, USA.

Anonymous, 2014. ASTM D2974-14, Standard Test Methods for Moisture, Ash, and Organic Matter of Peat and Other Organic Soils. ASTM International, West Conshohocken, PA, (www.astm.org).

Araújo, T.F., Ferreira, C.L.D.L.F., 2013. The genus Enterococcus as probiotic: safety concerns. Brazilian Archives of Biology and Technology, 56(3): 457-466.

Arias, O., Viña, S., Uzal, M., Soto, M., 2017. Composting of pig manure and forest green waste amended with industrial sludge. Science of The Total Environment, 586: 1228-1236.

Awasthi, M.K., Pandey, A.K., Bundela, P.S., Wong, J.WC., Li, R., Zhang, Z., 2016. Co-composting of gelatin industry sludge combined with organic fraction of municipal solid waste and poultry waste employing zeolite mixed with enriched nitrifying bacterial consortium, Bioresource Technology, 213: 181-189.

Białobrzewski, I., Mikš-Krajnik, M., Dach, J., Markowski, M., Czekała, W., Głuchowska, K., 2015. Model of the sewage sludge-straw composting process integrating different heat generation capacities of mesophilic and thermophilic microorganisms. Waste Management, 43: 72-83.

Bouteleux, C., Saby, S., Tozza, D., Cavard, J., Lahoussine, V., Hartemann, P., Mathieu, L., 2005. Escherichia coli behavior in the presence of organic matter released by algae exposed to water treatment chemicals. Applied and Environmental Microbiology, 71(2): 734-740.

Burdett, I., Kirkwood, T., Whalley, J., 1986. Growth kinetics of individual Bacillus subtilis cells and correlation with nucleoid extension. Journal of Bacteriology, 167(1): 219-230.

Canet, R., Pomares, F., Cabot, B., Chaves, C., Ferrer, E., Ribó, M., Albiach, M.R., 2008. Composting olive mill pomace and other residues from rural southeastern Spain. Waste Management, 28(12): 2585-2592.

Delgado-Moreno, L., Peña, A., 2009. Compost and vermicompost of olive cake to bioremediate triazinescontaminated soil. Science of The Total Environment, 407(5): 1489-1495.

Flowers, T., Williams, S., 1977. Measurement of growth rates of Streptomycetes: comparison of turbidimetric and gravimetric techniques. Microbiology, 98(1): 285-289.

Grube, M., Lin, J., Lee, P., Kokorevicha, S., 2006. Evaluation of sewage sludge-based compost by FTIR spectroscopy. Geoderma, 130(3): 324-333.

Gtari, M., Ghodhbane-Gtari, F., Nouioui, I., Beauchemin, N., Tisa, L.S., 2012. Phylogenetic perspectives of nitrogen-fixing actinobacteria. Archieve Microbiolology, 194(1): 3-11.

Hou, N., Wen, L., Cao, H., Liu, K., An, X., Li, D., Wang, H., Du, X., Li, C., 2017. Role of psychrotrophic bacteria in organic domestic waste composting in cold regions of China. Bioresource Technology, 236: 20-28.

Jukes, T., Cantor, C., 1969. Evolution of Protein Molecules.Academic, New York.

Kent, A.D., Triplett, E.W., 2002. Microbial communities and their interactions in soil and rhizosphere ecosystems. Annual Review Microbiololgy, 56: 211236

Krishnan, Y., Bong, C.P.C., Azman, N.F., Zakaria, Z., Abdullah, N., Ho, C.S., Lee, C.T., Hansen, S.B., Hara, H., 2017. Co-composting of palm empty fruit bunch and palm oil mill effluent: Microbial diversity 
and potential mitigation of greenhouse gas emission. Journal of Cleaner Production, 146: 94-100.

Lane, D.J., 1991. 16S/23S rRNA sequencing. In: E. Stackebrandt and M. Goodfellow (Eds.), Nucleic Acid Techniques in Bacterial Systematics, John Wiley and Sons, New York, pp: 115-175.

Lennox, E.S., 1955. Transduction of linked genetic characters of the host by bacteriophage P1. Virology, 1: 190.

Lim, S.-S., Park, H.-J., Hao, X., Lee, S.-I., Jeon, B.-J., Kwak, J.-H., Choi, W.-J., 2017. Nitrogen, carbon, and dry matter losses during composting of livestock manure with two bulking agents as affected by coamendments of phosphogypsum and zeolite. Ecological Engineering, 102: 280-290.

Liu, N., Zhou, J., Han, L., Ma, S., Sun, X., Huang, G., 2017. Role and multi-scale characterization of bamboo biochar during poultry manure aerobic composting. Bioresource Technology, 241: 190-199.

Ludwig, W., Schleifer, K.-H., Whitman, W.B., 2009. Bergey's manual of systematic bacteriology. In: P. De Vos, G.M. Garrity, D. Jones, N.R. Krieg, W. Ludwig, F.A. Rainey, K.-H. Schleifer, W.B. Whitman (Eds.), Class I. Bacilli Class Nov, Springer, New York, pp. 19-20.

Manu, M., Kumar, R., Garg, A., 2017. Performance assessment of improved composting system for food waste with varying aeration and use of microbial inoculum. Bioresource Technology, 234: 167-177.

Meng, L., Li, W., Zhang, S., Wu, C., Lv, L., 2017. Feasibility of co-composting of sewage sludge, spent mushroom substrate and wheat straw. Bioresource Technology, 226: 39-45.

Mohammadipanah, F., Hamedi, J., Spröer, C., Rohde, M., Del Carmen Montero-Calasanz, M., Klenk, H.-P., 2014. Streptomyces zagrosensis sp. nov., isolated from soil. International Journal of Systematic and Evolutionary Microbiology, 64(10): 3434-3440.

Neugebauer, M., Sołowiej, P., 2017. The use of green waste to overcome the difficulty in small-scale composting of organic household waste. Journal of Cleaner Production, 156: 865-875.

Pandey, P.K., Vaddella, V., Cao, W., Biswas, S., Chiu, C., Hunter, S., 2016. In-vessel composting system for converting food and green wastes into pathogen free soil amendment for sustainable agriculture. Journal of Cleaner Production, 139: 407-415.

Paradelo, R., Moldes, A.B., Barral, M.T., 2013. Evolution of organic matter during the mesophilic composting of lignocellulosic winery wastes. Journal of Environmental Management, 116: 18-26.

Pitcher, D., Saunders, N., Owen, R., 1989. Rapid extraction of bacterial genomic DNA with guanidium thiocyanate. Letters in Applied Microbiology, 8(4): 151-156.

Prakasham, R., Rao, C.S., Sarma, P., 2006. Green gram husk-an inexpensive substrate for alkaline protease production by Bacillus sp. in solid-state fermentation. Bioresource Technology, 97(13): 1449-1454.
Saitou, N., Nei, M., 1987. The neighbor-joining method: a new method for reconstructing phylogenetic trees. Molecular Biology and Evolution, 4(4): 406-425.

Sembiring, L., Ward, A.C., Goodfellow, M., 2000. Selective isolation and characterisation of members of the Streptomyces violaceusniger clade associated with the roots of Paraserianthes falcataria. Antonie van Leeuwenhoek, 78(3): 353-366.

Shirling, E.B., Gottlieb, D., 1966. Methods for characterization of Streptomyces species. International Journal of Systematic Bacteriology, 16: 313-340.

Soobhany, N., Gunasee, S., Rago, Y.P., Joyram, H., Raghoo, P., Mohee, R., Garg, V.K., 2017. Spectroscopic, thermogravimetric and structural characterization analyses for comparing municipal solid waste composts and vermicomposts stability and maturity. Bioresource Technology, 236: 11-19.

Tamura, K., Stecher, G., Peterson, D., Filipski, A., Kumar, S., 2013. MEGA6: molecular evolutionary genetics analysis version 6.0. Molecular Biology and Evolution, 30(12): 2725-2729.

Tandy, S., Healey, J.R., Nason, M.A., Williamson, J.C., Jones, D.L., Thain, S.C., 2010. FT-IR as an alternative method for measuring chemical properties during composting. Bioresource Technology, 101(14): 5431-5436.

Tang-um, J., Niamsup, H., 2012. Extracellular amylase activity from endophytic Streptomyces griseoflavus P4. Chiang Mai Journal of Science, 39: 346-350.

Tran, Q.N.M., Mimoto, H., Nakasaki, K., 2015. Inoculation of lactic acid bacterium accelerates organic matter degradation during composting. International Biodeterioration \& Biodegradation, 104: 377-383.

Van Fan, Y., Lee, C.T., Klemeš, J.J., Chua, L.S., Sarmidi, M.R., Leow, C.W., 2018. Evaluation of effective microorganisms on home scale organic waste composting. Journal of Environmental Management, 216: 41-48

Vázquez, M., Soto, M., 2017. The efficiency of home composting programmes and compost quality. Waste Management, 64: 39-50.

Xie, X.Y., Zhao, Y., Sun, Q.H., Wang, X.Q., Cui, H.Y., Zhang, X., Li, Y.J., Wei, Z.M., 2017. A novel method for contributing to composting start-up at low temperature by inoculating cold-adapted microbial consortium. Impact of phosphate-solubilizing bacteria inoculation methods on phosphorus transformation and long-term utilization in composting. Bioresource Technology, 238: 39-47.

Yuan, J., Chadwick, D., Zhang, D., Li, G., Chen, S., Luo, W., Du, L., He, S., Peng, S., 2016. Effects of aeration rate on maturity and gaseous emissions during sewage sludge composting. The efficiency of home composting programmes and compost quality. Waste Management, 56: 403-410. 